\title{
Morphological and morphometric changes in the Purkinje cells of patients with essential tremor
}

IOANNIS MAVROUDIS ${ }^{1-3}$, DIMITRIOS KAZIS ${ }^{2}$, FOIVOS PETRIDIS ${ }^{2,3}$, SIMELA CHATZIKONSTANTINOU $^{2}$, ELENI KARANTALI ${ }^{2}$, SAMUEL N. NJAU $^{4}$, VASILIKI COSTA ${ }^{3}$, ALIN CIOBICA $^{5-7}$, CONSTANTIN TRUS $^{8}$, IOANA MIRUNA BALMUS ${ }^{9}$ and STAVROS J. BALOYANNIS ${ }^{3,10}$

${ }^{1}$ Department of Neurology, Leeds Teaching Hospitals, NHS Trust, Leeds, LS1 3EX, United Kingdom;

${ }^{2}$ Third Department of Neurology; ${ }^{3}$ Laboratory of Neuropathology and Electron Microscopy;

${ }^{4}$ Department of Forensic Medicine and Toxicology, Aristotle University of Thessaloniki, Thessaloniki 54636, Greece;

${ }^{5}$ Department of Biology, Faculty of Biology, Alexandru Ioan Cuza University; ${ }^{6}$ Center of Biomedical Research,

Romanian Academy, Iasi 700506; ${ }^{7}$ Faculty of Medicine, 'Grigore T. Popa', University of Medicine and Pharmacy,

Iasi $700115 ;{ }^{8}$ Department of Morphological and Functional Sciences, Faculty of Medicine, Dunarea de Jos University, Galati 800008; ${ }^{9}$ Department of Exact Sciences and Natural Sciences, Institute of Interdisciplinary Research, Alexandru Ioan Cuza University of Iaşi, Iaşi 700057, Romania; ${ }^{10}$ Research Institute for Alzheimer's Disease, Heraklion Langada, Thessaloniki 57200, Greece

Received March 22, 2021; Accepted July 30, 2021

DOI: $10.3892 / \mathrm{etm} .2021 .11090$

\begin{abstract}
Essential tremor (ET) is a progressive neurological syndrome characterised by involuntary tremors of the hands or arms, head, jaw and voice. The pathophysiology of ET is not clearly understood yet. However, previous studies have reported several changes in the brain of patients with ET. One of the brain areas extensively investigated is the cerebellum. In the present study, a morphometric analysis of Purkinje cells in patients with ET and ET-plus was performed, and subsequently compared with normal controls using the Golgi silver staining method and 3D neuronal reconstruction. Substantial morphological changes were uncovered in the Purkinje cells of patients with ET compared with normal controls, including a decreased dendritic length and field density, an overall loss of terminal branches and a decreased density of dendritic spines.
\end{abstract}

\section{Introduction}

Essential tremor (ET) is a chronic progressive neurological syndrome characterised by involuntary tremors of the hands

Correspondence to: Dr Alin Ciobica, Department of Biology, Faculty of Biology, Alexandru Ioan Cuza University, 11 Bulevardul Carol I, Iasi 700506, Romania

E-mail: alin.ciobica@uaic.ro

Dr Constantin Trus, Department of Morphological and Functional Sciences, Faculty of Medicine, Dunarea de Jos University, 47 Domneasca Street, Galati 800008, Romania

E-mail: dilconstantin@yahoo.com

Key words: essential tremor, Purkinje cells, Golgi method or arms, and progressively of the head, jaw and voice (1-4). ET can present with heterogeneous clinical phenotypes, and some patients manifest extensive and complex deficits (5-10). ET is often considered a hereditary benign condition, with an isolated tremor and no further neurological signs (11); however, it is clearly defined in the new classification of tremors that ET is a syndrome that may have multiple aetiologies (5). The new diagnostic criteria for ET require the occurrence of isolated action tremor syndrome of the bilateral upper limbs with a minimum duration of 3 years, and/or tremors in the head, voice and lower limbs and mild neurological signs, such as dystonia, ataxia and/or Parkinsonism. Soft neurological deficits, such as mild memory impairment and impaired tandem gait, are also accepted; however, such patients are now diagnosed with ET-plus syndrome (5).

Numerous studies have been conducted to clarify the pathological, neuroimaging, physiological and clinical features of ET; however, the pathophysiological mechanism is not clearly understood (6-48). The cerebellum is one of the brain structures that has been extensively investigated at the macroscopic and microscopic levels (6-8). A number of studies have reported different levels of structural and functional alterations in the cerebellum of ETs. For example, neuroimaging studies have revealed a reduction in the volume of the cerebellar vermis with marked atrophy, atrophy of the cerebellar cortex, white matter changes in multiple cerebellar areas, and overactivity of the deep cerebellar nuclei and the cerebellar cortex and their connections (11-29). Meanwhile, additional studies have failed to identify any significant differences in the cerebellum between patients with ET and normal controls (NCs) $(11,15,16,28-40)$. Neuropathological studies have also reported heterogeneous findings, with a decrease in the linear density of Purkinje cells, alterations in dendritic arborisation, axonal torpedoes, heterotopic Purkinje cells, hypertrophy of 
the basket cells and decreased climbing fibre-Purkinje cell synaptic density $(29,44-50)$.

The present study investigated the morphological and morphometric changes in Purkinje cells in ET and ET-plus brains compared with age-matched control brains.

\section{Materials and methods}

Patients with ET and NC samples. In the present study, the morphology of the dendritic arborisation of Purkinje cells from different parts of the cerebellum was analysed in 12 patients with ET ( 7 males and 5 females) and 15 individuals ( 8 males and 7 females) with no history of neurological conditions, who died accidentally and were used as NC samples (Table I). The mean age was $61.3 \pm 6.4$ years (range, $50-74$ years) and $65.6 \pm 6.0$ years (range, 50-74 years) for patients with ET and NCs, respectively. Three parts were excised from the cerebellum: The first from the flocculonodular lobe or lobule $\mathrm{X}$, the second from the anterior lobe (lobule IV) and the third from the posterior lobe (lobule crus I). These parts were selected as representative parts of the three functional divisions of the cerebellum. All the brain tissues were obtained from the Laboratory of Forensic Medicine and Toxicology of the Aristotle University of Thessaloniki between January 2009 and December 2016. For each brain, written informed consent was obtained from the relatives of the deceased. The research was performed in full accordance with the Greek Democracy legislation (v. 2472/1997, 2819/2000, 2915/2001, 3235/2004, 3471/2006) and the Committee for Research Deontology Principles of the Aristotle University of Thessaloniki (ethical approval no. 12/2/4431/2019) (51). The average time from death to autopsy for all individuals was $8 \pm 2.9$ h. All patients in the ET group were clinically diagnosed with ET. Their history and neurological examination were retrospectively reviewed, and they were divided into three groups: ET with head and arm tremor $($ ET-h; $n=5)$; ET with arms tremor only (ET-a; $n=4)$; and ET-plus $(n=3)$. An independent neuropathologist who was blinded to the medical history examined the brain. After the autopsy, the brains were immersed at $18^{\circ} \mathrm{C}$ in a $10 \%$ solution of formaldehyde for 25 days (52). Subsequently, small parts of the anterior, posterior and flocculonodular lobes were excised and used for Golgi staining at $120 \mu \mathrm{m}$-thick sections, as described in our previous work (52), and studied with an Axiostar plus Carl Zeiss light microscope at a standard (magnification, $\mathrm{x} 400$ ). Golgi method stains the whole dendritic field and makes the tracing of cells possible in a 3 -dimensional manner.

Cell selection criteria. Based on the criteria suggested by Jacobs et al (53), 25 Purkinje cells were selected from each brain. To avoid experimental bias, all selected cells were randomly pooled and were assigned serial numbers, and every third cell was then chosen.

Neuronal tracing and dendritic quantification. Neuronal tracing and dendritic measurements were performed as described in our previous study (52) using a motorised XYZ microscope stage system (MLS203/MZS500-E; ThorLabs, Inc.), with the movement on the $\mathrm{Z}$-axis being controlled by the MZS500-E-Z-Axis Piezo Stage and Controller Kit, with
Table I. Demographic features of patients and NCs.

\begin{tabular}{lccl}
\hline A, Patients with ET & & & \\
\hline Case & Age, years & Sex & Diagnosis \\
\hline 1 & 57 & M & ET-h \\
2 & 68 & M & ET-a \\
3 & 50 & M & ET-a \\
4 & 62 & F & ET-h \\
5 & 63 & M & ET-plus \\
6 & 61 & F & ET-a \\
7 & 74 & F & ET-plus \\
8 & 55 & M & ET-h \\
9 & 63 & M & ET-plus \\
10 & 62 & F & ET-h \\
11 & 59 & F & ET-a \\
12 & 54 & M & ET-a \\
Average/total & $61.3 \pm 6.4$ & $7 \mathrm{M} / 5 \mathrm{~F}$ & \\
\hline
\end{tabular}

$\mathrm{B}, \mathrm{NCs}$

\begin{tabular}{cccc}
\hline Case & Age, years & Sex & Diagnosis \\
\hline 1 & 67 & $\mathrm{M}$ & $\mathrm{NA}$ \\
2 & 59 & $\mathrm{~F}$ & $\mathrm{NA}$ \\
3 & 69 & $\mathrm{~F}$ & $\mathrm{NA}$ \\
4 & 72 & $\mathrm{~F}$ & $\mathrm{NA}$ \\
5 & 70 & $\mathrm{M}$ & $\mathrm{NA}$ \\
6 & 62 & $\mathrm{M}$ & $\mathrm{NA}$ \\
7 & 68 & $\mathrm{M}$ & $\mathrm{NA}$ \\
8 & 62 & $\mathrm{~F}$ & $\mathrm{NA}$ \\
9 & 63 & $\mathrm{M}$ & $\mathrm{NA}$ \\
10 & 74 & $\mathrm{~F}$ & $\mathrm{NA}$ \\
11 & 71 & $\mathrm{M}$ & $\mathrm{NA}$ \\
12 & 69 & $\mathrm{~F}$ & $\mathrm{NA}$ \\
13 & 66 & $\mathrm{~F}$ & $\mathrm{NA}$ \\
14 & 50 & $\mathrm{M}$ & $\mathrm{NA}$ \\
15 & 63 & $\mathrm{M}$ & $\mathrm{NA}$ \\
Average/total & $65.6 \pm 6.0$ & $8 \mathrm{M} / 7 \mathrm{~F}$ & \\
\hline
\end{tabular}

Average values are presented as the mean $\pm \mathrm{SD}$. M, male; F, female; ET, essential tremor; ET-a, ET with arm tremor only; ET-h, ET with head and arm tremor; NC, normal control; NA, not applicable.

the aim of the APC software provided by Thorlabs, Inc. with a JogStep of $1 \mu \mathrm{m}$ a Travel Range of $250 \mu \mathrm{m}$. The video captures were analysed in digital image sequences of 200 serial pictures. They were then imported into neuromantic application with the help of which the cells were traced and quantified along $\mathrm{x}^{-}, \mathrm{y}$ - and $\mathrm{z}$-coordinates (52). Neuronal tracing was performed using a semi-automatic form by two different investigators. All the measurements were used for statistical analysis. The quantitative evaluation of the dendritic trees was based on the method suggested by Uylings et al (54). 
Table II. ANOVA analysis of Purkinje cell properties.

A, Vermis

\begin{tabular}{lccccc}
\hline Parameter & ET-a & ET-h & ET-plus & NC & F-value \\
\hline Total dendritic length, $\mu \mathrm{m}$ & $9,487.73 \pm 551.06$ & $6,361.28 \pm 661.17^{\mathrm{a}}$ & $9,388.75 \pm 486.88^{\mathrm{b}}$ & $9,507 \pm 1053.13^{\mathrm{c}}$ & 922.1 \\
Number of terminals & $273.84 \pm 14.36$ & $199.86 \pm 27.04^{\mathrm{d}}$ & $276.12 \pm 14.64^{\mathrm{c}}$ & $288.94 \pm 16.66^{\mathrm{c}, \mathrm{f}, \mathrm{f}}$ & 915.43 \\
Branch length, $\mu \mathrm{m}$ & $562.9 \pm 33.79$ & $513.25 \pm 35.51$ & $570.56 \pm 39.05^{\mathrm{a}, \mathrm{c}}$ & $587.35 \pm 37.68^{\mathrm{a}, \mathrm{c}}$ & 151.89 \\
Branch order & $26.38 \pm 1.19$ & $20.24 \pm 2.48$ & $26.61 \pm 1.37$ & $27.04 \pm 0.88$ & 816.06 \\
Spines & $9.73 \pm 0.67$ & $7.87 \pm 0.71^{\mathrm{a}}$ & $9.84 \pm 0.68^{\mathrm{g}}$ & $9.37 \pm 0.93^{\mathrm{f}, \mathrm{g}}$ & 290.99 \\
\hline
\end{tabular}

B, Hemispheres

\begin{tabular}{lccccc}
\hline Parameter & ET-a & ET-h & ET-plus & NC & F-value \\
\hline Total dendritic length, $\mu \mathrm{m}$ & $7,889.4 \pm 1,387.22^{\mathrm{g}, \mathrm{h}}$ & $7,794.89 \pm 1,017.91^{\mathrm{b}, \mathrm{c}}$ & $9,407.22 \pm 642.27^{\mathrm{a}, \mathrm{b}}$ & $10,757.3 \pm 1,666.24^{\mathrm{a}, \mathrm{c}, \mathrm{f}}$ & 257.33 \\
Number of terminals & $202.72 \pm 23.98$ & $219.01 \pm 17.73^{\mathrm{d}}$ & $306.86 \pm 23.04^{\mathrm{d}}$ & $325.69 \pm 14.39^{\mathrm{d}, \mathrm{h}}$ & $1,871.33$ \\
Branch length, $\mu \mathrm{m}$ & $531.66 \pm 31.72$ & $538.44 \pm 31.54^{\mathrm{a}}$ & $594.69 \pm 36.65^{\mathrm{d}, \mathrm{g}}$ & $597.62 \pm 36.54^{\mathrm{d}, \mathrm{g}}$ & 214.29 \\
Branch order & $22.96 \pm 1.66$ & $24.64 \pm 1.58^{\mathrm{d}}$ & $28.41 \pm 1.75^{\mathrm{a}, \mathrm{c}}$ & $30.61 \pm 1.62^{\mathrm{a}, \mathrm{c}, \mathrm{e}}$ & 890.35 \\
Spines & $7.75 \pm 0.67$ & $7.4 \pm 0.49^{\mathrm{d}}$ & $9.76 \pm 0.66^{\mathrm{a}}$ & $9.98 \pm 0.68^{\mathrm{a}}$ & 902.82 \\
\hline
\end{tabular}

${ }^{\mathrm{a} P}<0.001$ vs. ET-a; ${ }^{\text {bP }}<0.01$ vs. ET-h; ${ }^{\mathrm{c} P}<0.0001$ vs. ET-h; ${ }^{\mathrm{d}} \mathrm{P}<0.0001$ vs. ET-a; ${ }^{\mathrm{e}} \mathrm{P}<0.01$ vs. ET-a; ${ }^{\mathrm{f}} \mathrm{P}<0.001$ vs. ET-plus; ${ }^{\mathrm{g}} \mathrm{P}<0.001$ vs. ET-h; ${ }^{\mathrm{h}} \mathrm{P}<0.0001$ vs. ET-plus. Data are presented as the mean \pm SD. ET, essential tremor; ET-a, ET with arm tremor only; ET-h, ET with head and arm tremor; NC, normal control; vs., versus.

Dendritic measures and Sholl's analysis. Neuromantic automatically provides all the measurements for the total length of dendritic trees, total number of dendritic segments and terminal branches, total dendritic area and total dendritic volume, which were analysed further in the statistical analysis. The tracings were additionally analysed using the Fiji (version 2017; Fiji) and Simple Neurite Tracer plugin on ImageJ (v.1.8; National Institutes of Health) based on Sholl's method of concentric spheres centred on the cell's soma at intervals of $10 \mu \mathrm{m}(55)$.

Spine counts. Spine counts were performed for 500 images. Images were captured with an AxioCam HR (Zeiss GmbH), at a magnification of $\mathrm{x} 1,000$, with an Axiostar plus photomicroscope. All the visible spines were measured on the three segments of the dendritic field: The first segment, 20-30 $\mu \mathrm{m}$ in length at a distance of $50 \mu \mathrm{m}$ from the cell soma; the second segment, $20-30 \mu \mathrm{m}$ in length within $150 \mu \mathrm{m}$; and the third segment, 20-30 $\mu \mathrm{m}$ within $250 \mu \mathrm{m}$ from the cell body.

Purkinje cell density. The linear density of Purkinje cells was measured in Nissl-stained specimens on 30 randomly selected images (magnification, x20), using ImageJ (v.1.8; National Institutes of Health) and the cell counter plugin (56).

Statistical analysis. RStudio (version, 1.4.1717) with R (version, 4.1.1) was used for the statistical analysis and plotting of graphs (57). All data was stored in comma-separated value files and presented for statistical analysis as data frames. One-way ANOVA followed by Tukey's post hoc test was used to determine whether significant differences existed across the independent parameters of Purkinje cells among the four groups. ANOVA mixed-effects model followed by Tukey's post hoc test was used for the statistics of Sholl's analysis, based on an R Script. Pearson's correlation test was performed to identify any correlation between the autolysis time and Purkinje cell dendritic complexity variables. $\mathrm{P}<0.05$ was considered to indicate a statistically significant difference.

\section{Results}

Total dendritic length. The total dendritic length of Purkinje cells from the cerebellar vermis was significantly lower in the ET-h group compared with the ET-a, ET-plus and NC groups (Table II). No significant difference was identified between the ET-a, ET-plus and NC groups (Fig. 1A). However, the total dendritic length of Purkinje cells in the cerebellar hemispheres was significantly decreased in the ET-a group compared with ET-plus and NC groups (Fig. 1B). Similarly, the difference was statistically significant between the ET-h, ET-plus and $\mathrm{NC}$ groups, and between the ET-plus and NC groups. No significant differences were found between the ET-a and ET-h groups (Fig. 1B).

Terminal branches. The total number of terminal branches of Purkinje cells from the cerebellar vermis was significantly lower in the ET-h group compared with the ET-a, ET-plus and NC groups. No significant difference was found between the ET-a and ET-plus groups, but there was a statistically significant difference between the ET-a and NC groups, and between the ET-plus and NC groups (Figs. 1C and 2 and Table II). Purkinje cells from the cerebellar hemispheres from the ET-a group had significantly fewer terminal branches than 
A

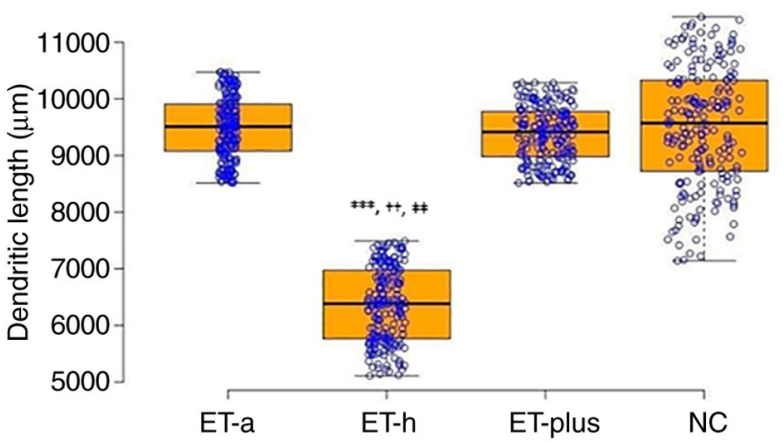

C

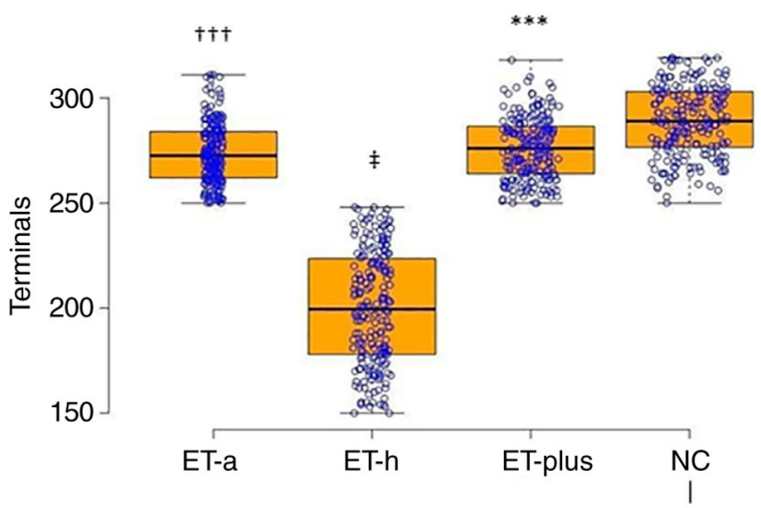

B

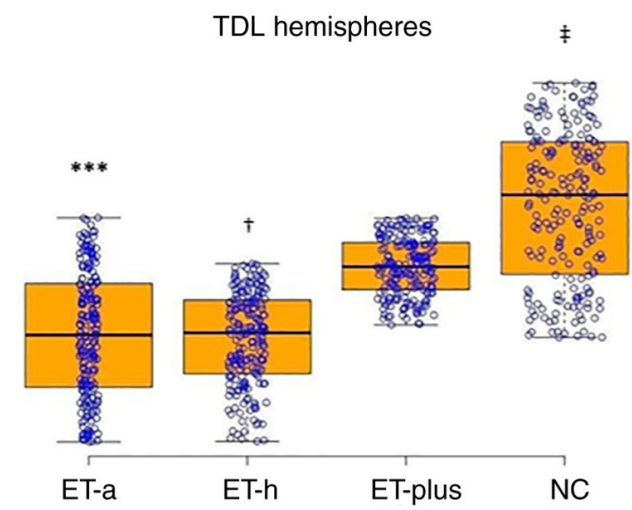

Terminals hemispheres

$\mathrm{D}$

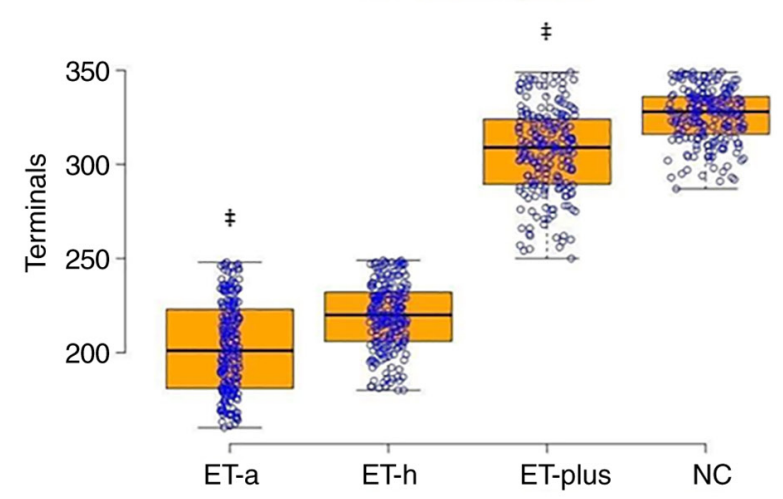

Figure 1. TDL of Purkinje cells from (A) the cerebellar vermis and (B) the cerebellar hemispheres. Total number of terminal branches of the Purkinje cells from (C) the cerebellar vermis and (D) the hemispheres. Results are presented as boxplot charts and the statistical significance in ANOVA test was expressed as symbols (A) ${ }^{* * * *} \mathrm{P}<0.001$ ET-h vs. ET-a; ${ }^{\dagger} \mathrm{P}<0.003$ ET-h vs. ET-plus; ${ }^{*} \mathrm{P}<0.00001 \mathrm{ET}-\mathrm{h}$ vs. NC; (B) ${ }^{* * * *} \mathrm{P}<0.001$ ET-a vs. ET-plus, NC; ${ }^{*} \mathrm{P}<0.0001$ NC vs. ET-plus, ET-h; 'P<0.002 ET-h vs. ET-plus; (C) ${ }^{\ddagger}$ P $<0.0001$ ET-h vs. ET-a, ET-plus, NC; ${ }^{\dagger \dagger}$ P $<0.005$ ET-a vs. NC; ${ }^{* * *}$ P $<0.001$ ET-plus vs. NC; (D) ${ }^{\ddagger}$ P $<0.0001$ ET-a vs. ET-plus, ET-h, NC, ET-plus vs. NC. TDL, total dendritic length; ET, essential tremor; ET-a, ET with arm tremor only; ET-h, ET with head and arm tremor; NC, normal control.

the ET-plus, NC and the ET-h groups (Fig. 1D). In addition, the ET-plus group displayed a significantly lower number of terminal branches compared with the NC group (Fig. 1D).

Branch length and branch order. The mean branch length (Fig. 3A and Table II) and the maximum branch order of the cerebellar vermis were both significantly decreased in the ET-h group compared with the ET-plus and NC groups. The ET-a group also indicated a significantly lesser branch length and maximum branch order than the ET-plus and NC groups. The ET-plus group demonstrated a decreased branch length and branch order compared with the NC group. Purkinje cells from the cerebellar hemispheres exhibited a decreased branch length in the ET-a group compared with the other groups, and in the ET-h group compared with the ET-plus and NC groups. No statistically significant difference was observed between the ET-plus and NC groups (Fig. 3B). The maximum branch order was similarly decreased in the ET-h group compared with the other groups, in the ET-a group compared with the ET-plus and NC groups, and in the ET-plus group compared with the $\mathrm{NC}$ group.

Dendritic spines. The dendritic spine density was reduced in the ET-h group compared with the ET-a, ET-plus and NC groups in Purkinje cells from the cerebellar vermis; however, no significant difference was found between the ET-a and
ET-plus groups. The latter displayed notably more dendritic spines compared with Purkinje cells from the NC group (Figs. 4A and 5 and Table II). Meanwhile, Purkinje cells from the cerebellar hemispheres demonstrated a significant difference between the ET-h and ET-a groups, between the ET-plus and NC groups, between the ET-a and ET-plus, and between the ET-a and NC groups (Figs. 4B, 5 and Table II). Moreover, Pearson's correlation test did not reveal a significant correlation between autolysis time and dendritic and spinal measurements.

Sholl's analysis. Sholl's concentric circle analysis revealed significant restriction of the dendritic field of Purkinje cells from the cerebellar vermis and cerebellar hemispheres in the ET-h and ET-a groups compared with the ET-plus and NC groups for distances $>120 \mu \mathrm{m}$ from the cell soma (Fig. 6A and B). The areas under the curve also confirmed the significance of the differences in the overall dendritic field density (Fig. 6C).

\section{Discussion}

Multiple studies have reported neuropathological changes in ET, with morphological and morphometric alterations of Purkinje cells and Lewy bodies in the locus coeruleus; however, whether these changes are the characteristic features 

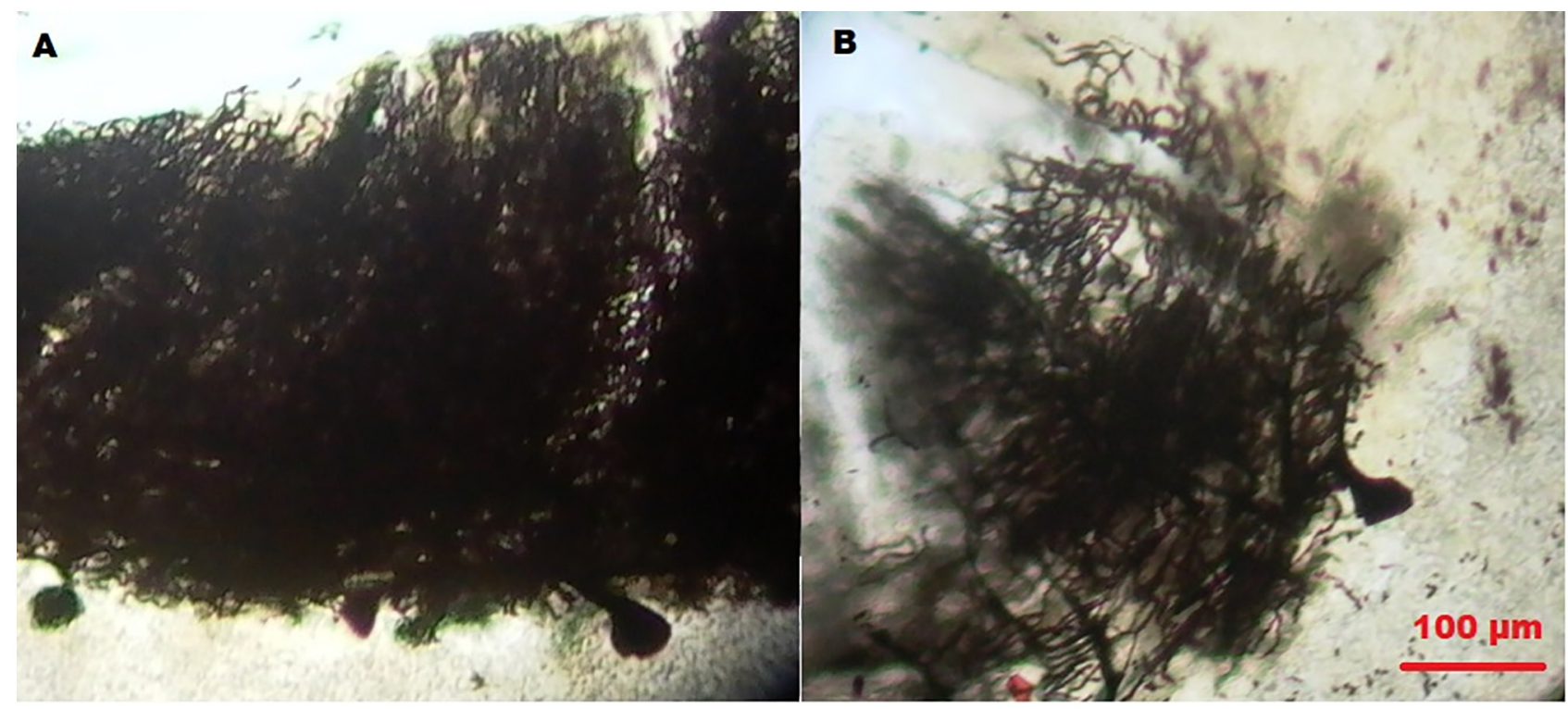

Figure 2. Representative images of Purkinje cells from the cerebellum from (A) a control and (B) a patient with essential tremor from the ET-h group, generated by the Golgi method. Magnification, x100. Scale bar, $100 \mu \mathrm{m}$.

A

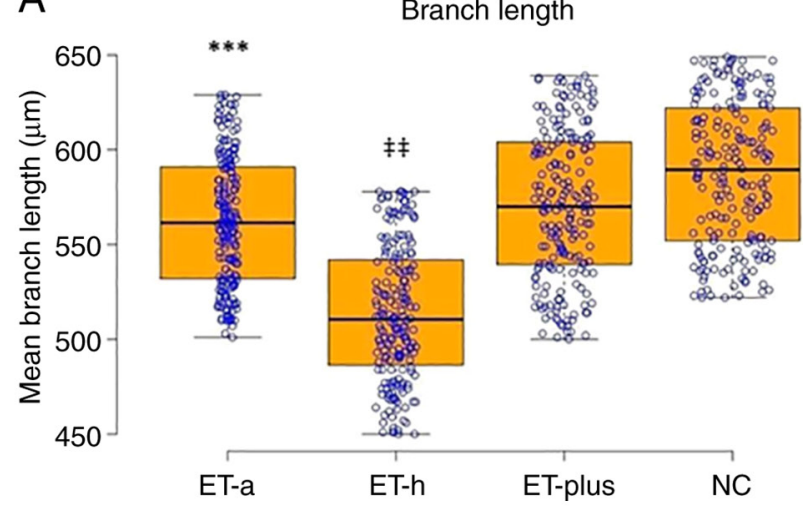

B

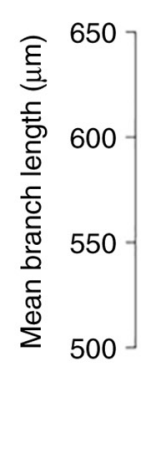

Branch length

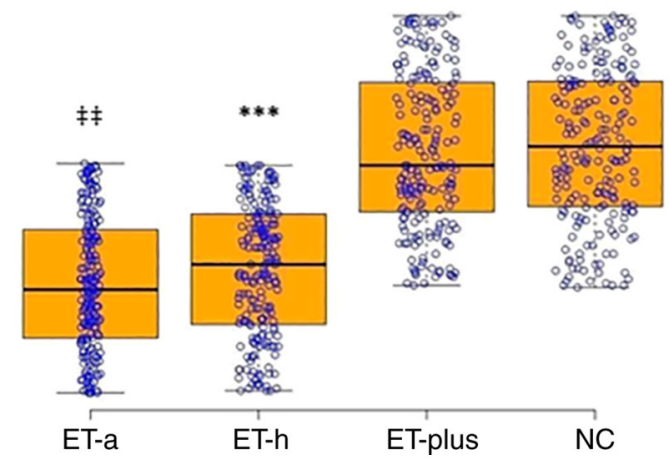

Figure 3. Mean branch length of Purkinje cells from (A) the vermis and (B) the cerebellar hemispheres (B). Results are presented as boxplot charts and the statistical significance in ANOVA test is expressed as symbols. (A) ${ }^{+} \mathrm{P}<0.00001$ ET-h vs. ET-plus, NC; ${ }^{* * * *} \mathrm{P}<0.001 \mathrm{ET}-\mathrm{a}$ vs. ET-plus, NC; (B) ${ }^{*} \mathrm{P}<0.00001$ ET-a vs. ET-plus, NC; ${ }^{* * *}$ P<0.001 ET-h vs. ET-a, ET-plus, NC. ET, essential tremor; ET-a, ET with arm tremor only; ET-h, ET with head and arm tremor; NC, normal control.

of the condition is unclear (15,16,11-49). One possible explanation may be that different types of essential tremor exhibit different pathological mechanisms and neuropathological backgrounds.

Two previous studies demonstrated a significant reduction in the linear Purkinje cell density in ET, and greater distances between single Purkinje cell bodies $(28,29)$; however, another study failed to confirm these findings (58). Further studies reported increased numbers of heterotopic Purkinje cells in ET, up to three times compared with controls (59), and certain morphological changes, with a substantial loss of dendritic spines, total dendritic length and restriction of the dendritic fields (44).

The most common neuropathological feature of ET is axonal changes, known as axonal torpedoes; they are focal swellings of Purkinje cell axons containing an accumulation of hyperphosphorylated neurofilaments and disrupted organelles, and can also be found in spinocerebellar ataxias $(46,47)$.
Additional changes, which could potentially explain the pathophysiology of ET, are also referred to as the basket cell morphology (47) and climbing fibre-Purkinje cells' synaptic density (49).

Patients with ET may have tremors of the hands, head, voice and rarely the jaw. According to the 2016 classification of ET, patients who develop soft neurological symptoms, such as mild rigidity, balance impairment or mild memory impairment are classified as experiencing ET-plus (5). However, whether ET-plus or ET are different entities remains controversial.

In the present study, significant morphological changes were found in Purkinje cells, including a decreased dendritic length and field density, an overall loss of terminal branches, and a decreased density of dendritic spines in ET patients compared with controls. Furthermore, ET patients were divided into three groups based on the revised criteria for ET. The results indicated that the ET-h group exhibited significant 
A

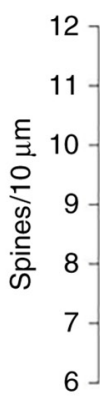

Dendritic spines vermis

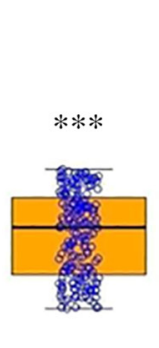

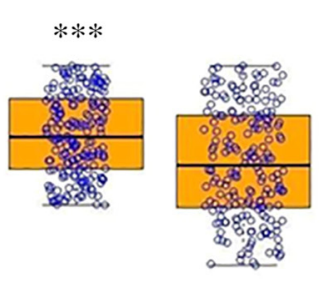

B

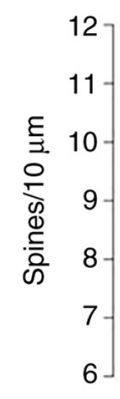

Dendritic spines hemispheres
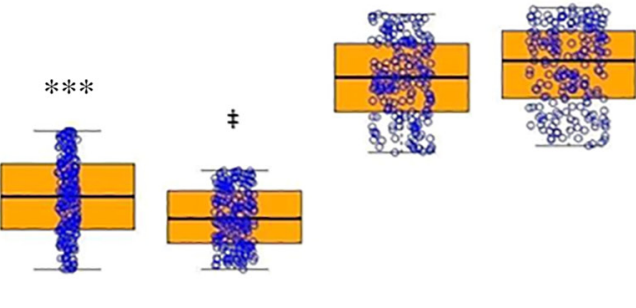

ET-a

ET-h

ET-plus NC

Figure 4. Dendritic spine density on Purkinje cells from the vermis (A), and the cerebellar hemispheres (B). Results are presented as boxplot charts and the statistical significance in ANOVA test is expressed as symbols (A) ${ }^{* * *} \mathrm{P}<0.001$ ET-h vs. ET-a, ET-plus, NC, ET-plus vs. NC; (B) ${ }^{\ddagger}$ P $<0.0001$ ET-h vs. ET-a; ${ }^{* * * *} \mathrm{P}<0.001$ ET-a vs. ET-plus, NC. ET, essential tremor; ET-a, ET with arm tremor only; ET-h, ET with head and arm tremor; NC, normal control.
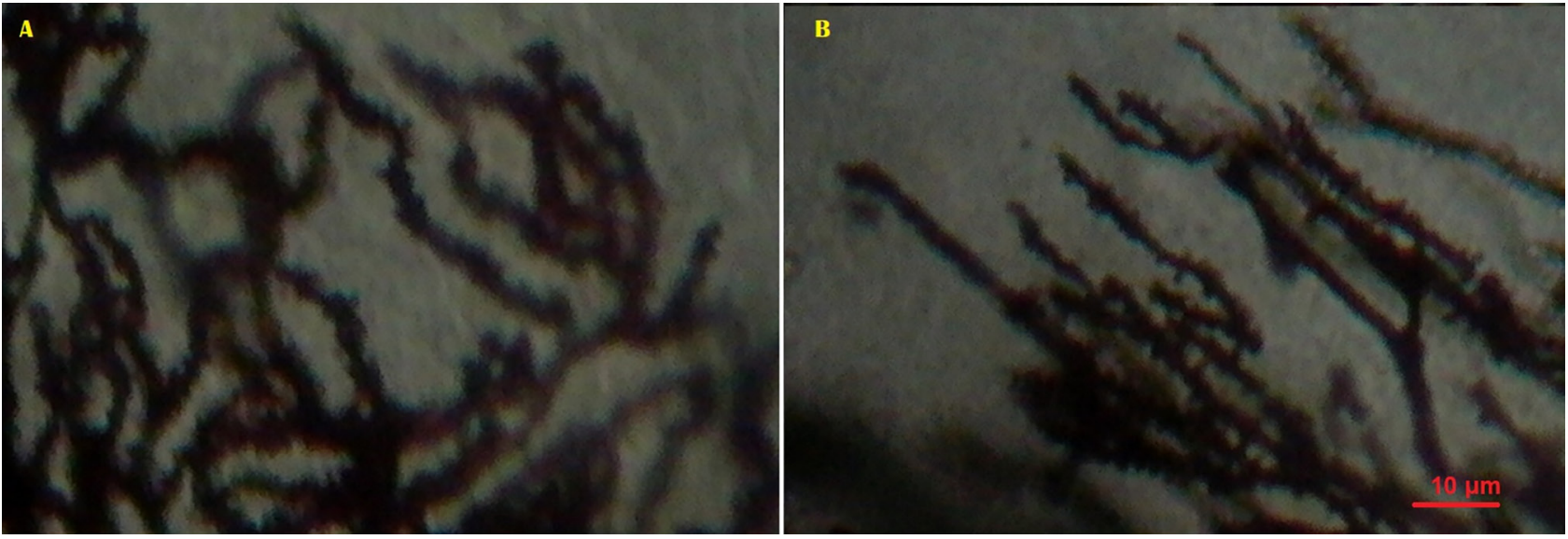

Figure 5. Representative images showing the dendritic spines in dendrites from Purkinje cells from (A) a control and (B) a patient with essential tremor, generated by the Golgi method, Magnification, x1,000. Scale bar, $10 \mu \mathrm{m}$.

changes in both the cerebellar vermis and hemispheres, while the ET-a group displayed significant differences only in Purkinje cells from the cerebellar hemispheres compared with controls. Meanwhile, Purkinje cells from patients with ET-plus demonstrated only minor changes. The significant loss of dendritic spines and terminal branches, which are the most plastic components of the dendritic field (52), could lead to a substantial decrease in the synaptic contacts of Purkinje cells. This could be of significant importance in the pathophysiology of ET.

The flocculonodular lobe of the cerebellum corresponds to the vestibulocerebellum and is functionally related to head movements, while the anterior and posterior lobes of the hemisphere are related to limb movements and movement scheduling $(60,61)$. Different Purkinje cell pathologies were identified in the different groups of the study, which could explain the different symptoms in each patient group. Patients with ET-a did not exhibit significant pathology in the Purkinje cells of the cerebellar vermis. However, patients with ET-a exhibited pathology in the cerebellar hemispheres, which are functionally related to Purkinje cells. Patients with ET-h exhibited pathology in the Purkinje cells of the cerebellar hemispheres and vermis. Patients with ET-plus did not display any significant pathology in the Purkinje cells of the cerebellum, which may suggest that this condition has a different pathophysiological background; however, whether these changes are primary and degenerative, or are instead compensatory, remains unclear.

The heterogeneous findings among the different groups of ET could correspond to clinical heterogeneity. Therefore, it can be assumed that ET-plus syndrome is different from ET syndrome in terms of not only pathology and physiopathology, but also clinical aspects. Although the cause of ET remains unknown, the morphological changes found in Purkinje cells could be the structural background of ET symptomatology. Differences in the Purkinje cell pathology between ET-h and ET-a also reflected the differences in the clinical presentation of ET.

\section{Acknowledgements}

Not applicable.

\section{Funding}

No funding was received. 

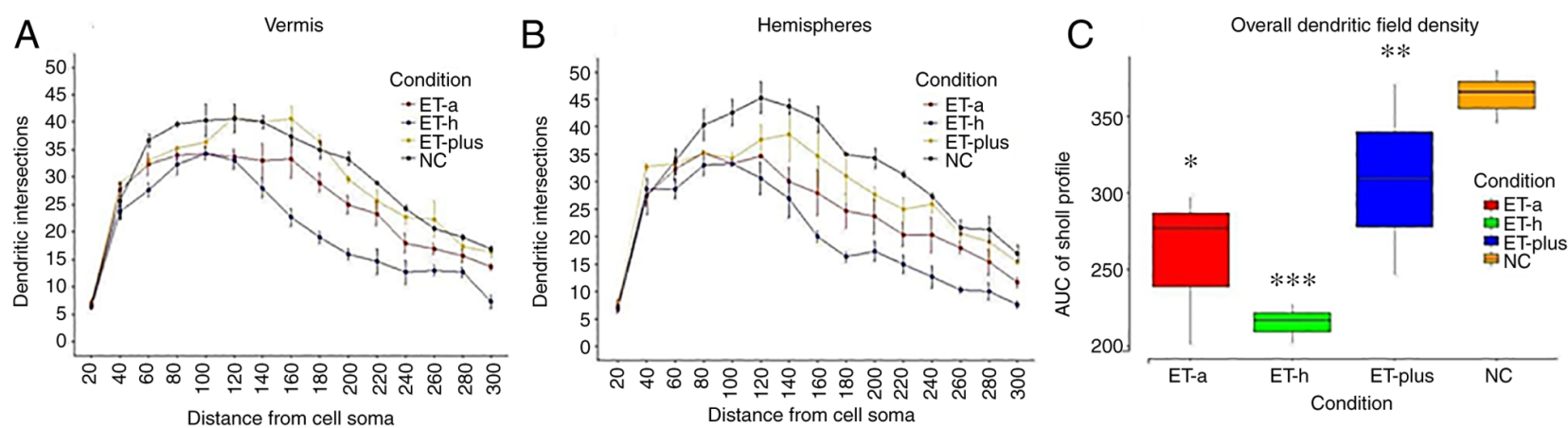

Figure 6. Sholl's analysis of Purkinje cells from (A) the vermis and (B) the cerebellar hemispheres, and (C) AUC analysis confirming the significant difference in the overall dendritic field density. Results are presented as line and boxplot charts and the statistical significance in ANOVA test was expressed as symbols (C) ${ }^{* * * *}$ P $<0.001$ ET-h vs. NC; ${ }^{*} \mathrm{P}<0.05$ ET-a vs. ET-h, ET-plus vs. NC; ${ }^{* *} \mathrm{P}<0.01$ ET-plus vs. ET-h. ET, essential tremor; ET-a, ET with arm tremor only; ET-h, ET with head and arm tremor; $\mathrm{NC}$, normal control; AUC, area under the curve.

\section{Availability of data and materials}

The datasets used and/or analyzed during the current study are available from the corresponding author on reasonable request.

\section{Authors' contributions}

IM made substantial contributions to conception and design of the study. DK, FP, SC and EK contributed to data acquisition and analysis. IM, DK, SNN, VC, AC, CT, IMB and SJB contributed to data interpretation and preparation of the manuscript. IM, VC, CT, IMB and SJB supervised the study and critically reviewed the manuscript. IM, DK, FP, SC, EK, AC, VC, CT and SJB confirm the authenticity of all the raw data. All authors have read and approved the final manuscript.

\section{Ethics approval and consent to participate}

The research was performed in full accordance with the Greek Democracy legislation (v. 2472/1997, 2819/2000, 2915/2001, 3235/2004, 3471/2006) and the Committee for Research Deontology Principles of the Aristotle University of Thessaloniki. The ethical approval number of this study was $12 / 2 / 4431 / 2019$. For each brain, written informed consent was obtained from the relatives of the deceased.

\section{Patient consent for publication}

Not applicable.

\section{Competing interests}

The authors declare that they have no competing interests.

\section{References}

1. Putzke JD, Whaley NR, Baba Y, Wszolek ZK and Uitti RJ: Essential tremor: Predictors of disease progression in a clinical cohort. J Neurol Neurosurg Psychiatry 77: 1235-1237, 2006.

2. Louis ED: The primary type of tremor in essential tremor is kinetic rather than postural: Cross-sectional observation of tremor phenomenology in 369 cases. Eur J Neurol 20: 725-727, 2013.
3. Cohen O, Pullman S, Jurewicz E, Watner E and Louis ED: Rest tremor in patients with essential tremor: Prevalence, clinical correlates, and electrophysiologic characteristics. Arch Neurol 60: 405-410, 2003.

4. Sternberg EJ, Alcalay RN, Levy OA and Louis ED: Postural and intention tremors: A detailed clinical study of essential tremor vs. Parkinson's disease. Front Neurol 4: 51, 2013.

5. Gitchel GT, Wetzel PA and Baron MS: Slowed saccades and increased square wave jerks in essential tremor. Tremor Other Hyperkinet Mov (NY) 3: tre-03-178-4116-2, 2013.

6. Louis ED, Galecki M and Rao AK: Four essential tremor cases with moderately impaired gait: How impaired can gait be in this disease? Tremor Other Hyperkinet Mov (NY) 3: tre-03-200-4597-1, 2013.

7. Benito-Leon J, Louis ED and Bermejo-Pareja F; Neurological Disorders in Central Spain (NEDICES) Study Group: Population-based case-control study of cognitive function in essential tremor. Neurology 66: 69-74, 2006.

8. Louis ED, Bromley SM, Jurewicz EC and Watner D: Olfactory dysfunction in essential tremor: A deficit unrelated to disease duration or severity. Neurology 59: 1631-1633, 2002.

9. Ondo WG, Sutton L, Vuong KD, Lai D and Jankovic J: Hearing impairment in essential tremor. Neurology 61: 1093-1097, 2003.

10. Shin H, Lee DK, Lee JM, Huh YE, Youn J, Louis ED and Cho JW: Atrophy of the cerebellar vermis in essential tremor: Segmental volumetric MRI analysis. Cerebellum 15: 174-181, 2016.

11. Quattrone A, Cerasa A, Messina D, Nicoletti G, Hagberg GE, Lemieux L, Novellino F, Lanza P, Arabia G and Salsone M: Essential head tremor is associated with cerebellar vermis atrophy: A volumetric and voxel-based morphometry MR imaging study. AJNR Am J Neuroradiol 29: 1692-1697, 2008 .

12. Klaming R, Kayano J, Bartsch H and Annese J: Multimodal longitudinal imaging and close monitoring of single-case studies may demonstrate the relationship between structural and behavioral markers of Essential Tremor. This poster (Program\#/Poster\#: 553.16/D49) was presented at the Annual Meeting of the Society for Neuroscience Nov 14-16 2011 in Washington, DC, USA.

13. Sharifi S, Nederveen AJ, Booij J and van Rootselaar AF: Neuroimaging essentials in essential tremor: A systematic review. Neuroimage Clin 5: 217-231, 2014.

14. Benito-Leon J, Alvarez-Linera J, Hernandez-Tamames JA, Alonso-Navarro H, Jimenez-Jimenez FJ and Louis ED: Brain structural changes in essential tremor: Voxel-based morphometry at 3-Tesla J Neurol Sci 287: 138-142, 2009.

15. Lin CH, Chen CM, Lu MK, Tsai CH, Chiou JC, Liao JR and Duann JR: VBM reveals brain volume differences between Parkinson's disease and essential tremor patients. Front Hum Neurosci 7: 247, 2013.

16. Klein JC, Lorenz B, Kang JS, Baudrexel S, Seifried C, van de Loo S, Steinmetz H, Deichmann R and Hilker R: Diffusion tensor imaging of white matter involvement in essential tremor. Hum Brain Mapp 32: 896-904, 2011.

17. Nicoletti G, Manners D, Novellino F, Condino F, Malucelli E, Barbiroli B, Tonon C, Arabia G, Salsone M, Giofre L, et al: Diffusion tensor MRI changes in cerebellar structures of patients with familial essential tremor Neurology 74: 988-994, 2010. 
18. Saini J, Bagepally BS, Bhatt MD, Chandran V, Bharath RD, Prasad C, Yadav R and Pal PK: Diffusion tensor imaging: Tract based spatial statistics study in essential tremor Parkinsonism Relat Disord 18: 477-482, 2012.

19. Shin DH, Han BS, Kim HS and Lee PH: Diffusion tensor imaging in patients with essential tremor. AJNR Am J Neuroradiol 29: 151-153, 2008.

20. Jia L, Jia-Lin S, Qin D, Qing L and Yan Z: Diffusion tensor imaging study in essential tremor. J Neuroimaging 21: 370-374, 2011.

21. Martinelli P, Rizzo G, Manners D, Tonon C, Pizza F, Testa C, Scaglione C, Barbiroli B and Lodi R: Diffusion-weighted imaging study of patients with essential tremor. Mov Disord 22 $1182-1185,2007$

22. Pinto AD, Lang AE and Chen R: The cerebellothalamocortical pathway in essential tremor. Neurology 60: 1985-1987, 2003.

23. Deuschl G and Elble RJ: The pathophysiology of essential tremor. Neurology 54 (11 Suppl 4): S14-S20, 2000.

24. Wills AJ, Jenkins IH, Thompson PD, Findley LJ and Brooks DJ: A positron emission tomography study of cerebral activation associated with essential and writing tremor. Arch Neurol 52: 299-305, 1995.

25. Paris-Robidas S, Brochu E, Sintes M, Emond V, Bousquet M, Vandal M, Pilote M, Tremblay C, Paolo TD, Rajput AH, et al: Defective dentate nucleus GABA receptors in essential tremor. Brain 135: 105-116, 2012

26. Rajput $\mathrm{AH}$, Adler $\mathrm{CH}$, Shill HA and Rajput A: Essential tremor is not a neurodegenerative disease. Neurodegener Dis Manag 2: $259-268,2012$

27. Louis ED and Vonsattel JP: The emerging neuropathology of essential tremor. Mov Disord 23: 174-182, 2008.

28. Axelrad JE, Louis ED, Honig LS, Flores I, Ross GW, Pahwa R, Lyons KE, Faust PL and Vonsattel JP: Reduced Purkinje cell number in essential tremor: A postmortem study. Arch Neurol 65: 101-107, 2008

29. Louis ED, Faust PL, Vonsattel JP, Honig LS, Rajput A, Robinson CA, Rajput A, Pahwa R, Lyons KE, Ross GW, et al: Neuropathological changes in essential tremor: 33 cases compared with 21 controls. Brain 130: 3297-3307, 2007.

30. Cameron E, Dyke JP, Hernandez N, Louis ED and Dydak U: Cerebral gray matter volume losses in essential tremor: A case control study using high resolution tissue probability maps. Parkinsonism Relat Disord 51: 85-90, 2018.

31. Daniels C, Peller M, Wolff S, Alfke K, Witt K, Gaser C, Jansen O, Siebner HR and Deuschl G: Voxel-based morphometry shows no decreases in cerebellar gray matter volume in essential tremor. Neurology 67: 1452-1456, 2006.

32. Fang W, Lv F, Luo T, Cheng O, Liao W, Sheng K, Wang X, Wu F, $\mathrm{Hu}$ Y, Luo J, et al: Abnormal regional homogeneity in patients with essential tremor revealed by resting-state functional MRI. PLoS One 8: e69199, 2013

33. Nicoletti V, Cecchi P, Frosini D, Pesaresi I, Fabbri S, Diciotti S Bonuccelli U, Cosottini M and Ceravolo R: Morphometric and functional MRI changes in essential tremor with and without resting tremor. J Neurol 262: 719-728, 2014.

34. Buijink AW, Broersma M, van der Stouwe AM, Sharifi S, Tijssen MA, Speelman JD, Maurits NM and van Rootselaar AF: Cerebellar atrophy in cortical myoclonic tremor and not in hereditary essential tremor-a voxel-based morphometry study. Cerebellum 15: 696-704, 2016.

35. Fang W, Chen H, Wang H, Zhang H, Puneet M, Liu M, Lv F, Luo T, Cheng O, Wang X and Lu X: Essential tremor is associated with disruption of functional connectivity in the ventral intermediate nucleus-motor cortex-cerebellum circuit. Hum Brain Mapp 37: 165-178, 2016.

36. Archer DB, Coombes SA, Chu WT, Chung JW, Burciu RG, Okun MS, Shukla AW and Vaillancourt DE: A widespread visually-sensitive functional network relates to symptoms in essential tremor. Brain 141: 472-485, 2018.

37. Gallea C, Popa T, Garcia-Lorenzo D, Valabregue R, Legrand AP, Marais L, Degos B, Hubsch C, Fernandez-Vidal S, Bardinet $\mathrm{E}$, et al: Intrinsic signature of essential tremor in the cerebello-frontal network. Brain 138: 2920-2933, 2015.

38. Cao H, Wang R, Luo X, Li X, Hallett M, Thompson-Westra J, Yang J, Qu Q and Yang X: A voxel-based magnetic resonance imaging morphometric study of cerebral and cerebellar gray matter in patients under 65 years with essential tremor. Med Sci Monit 24: 3127-3135, 2018.

39. Han Q, Hou Y and Shang H: A voxel-wise meta-analysis of gray matter abnormalities in essential tremor. Front Neurol 26: 495, 2018.

40. Luo R, Pan P, Xu Y and Chen L: No reliable gray matter changes in essential tremor. Neurol Sci 40: 2051-2063, 2019.
41. Radua J and Mataix-Cols D: Voxel-wise meta-analysis of grey matter changes in obsessive-compulsive disorder. $\mathrm{Br}$ J Psychiatry 195: 393-402, 2009.

42. Louis ED, Lee M, Babij R, Ma K, Cortes C, Vonsattel JP and Faust PL: Reduced Purkinje cell dendritic arborization and loss of dendritic spines in essential tremor. Brain 137: 3142-3148, 2014.

43. Louis ED, Vonsattel JP, Honig LS, Ross GW, Lyons KE and Pahwa R. Neuropathologic findings in essential tremor. Neurology 66: 1756-1759, 2006.

44. Louis ED, Yi H, Erickson-Davis C, Vonsattel JPG and Faust PL: Structural study of Purkinje cell axonal torpedoes in essential tremor. Neurosci Lett 450: 287-291, 2009.

45. Mann DM, Stamp JE, Yates PO and Bannister CM: The fine structure of the axonal torpedo in Purkinje cells of the human cerebellum. Neurol Res 1: 369-378, 1980.

46. Babij R, Lee M, Cortes E, Vonsattel JP, Faust PL and Louis ED: Purkinje cell axonal anatomy: Quantifying morphometric changes in essential tremor versus control brains. Brain 136: 3051-3061, 2013

47. Erickson-Davis CR, Faust PL, Vonsattel JP, Gupta S, Honig LS and Louis ED: 'Hairy baskets' associated with degenerative Purkinje cell changes in essential tremor. J Neuropathol Exp Neurol 69: 262-271, 2010

48. Lin CY, Louis ED, Faust PL, Koeppen AH, Vonsattel JP and Kuo SH: Abnormal climbing fibre-Purkinje cell synaptic connections in the essential tremor cerebellum. Brain 137: 3149-3159, 2014.

49. Their S, Lorenz D, Nothnagel M, Poremba C, Papengut F, Appenzeller S, Paschen S, Hofschulte F, Hussl AC, Hering S, et al: Polymorphisms in the glial glutamate transporter SLC1A2 are associated with essential tremor. Neurology 79: 243-248, 2012.

50. Yu SW, Chen CM, Chen YC, Chang CW, Chang HS, Lyu RK, Ro LS and Wu YR: SLC1A2 variant is associated with essential tremor in Taiwanese population. PLoS One 8: e71919, 2013.

51. Research Committee: Research Deontology Principles. 2nd edition, Aristotle University of Thessaloniki, Thessaloniki, Greece, pp22-25, 2010.

52. Mavroudis IA, Petrides F, Manani M, Chatzinikolaou F, Ciobică AS, Pădurariu M, Kazis D, Njau SN, Costa VG and Baloyannis SJ: Purkinje cells pathology in schizophrenia. A morphometric approach. Rom J Morphol Embryol 58: 419-424, 2017.

53. Jacobs B, Driscoll L and Schall M: Life-span dendritic and spine changes in areas 10 and 18 of human cortex: A quantitative Golgi study. J Comp Neurol 386: 661-680, 1997.

54. Uylings HBM, Van Eden CG, Parnavelas JG and Kalsbeek A: The prenatal and postnatal development of rat cerebral cortex. In: The Cerebral Cortex of the Rat. Kolb B and Tees RC (eds). MIT Press, Cambridge, MA, pp35-76, 1990.

55. Sholl DA: The organization of the visual cortex in the cat. J Physiol 124: 23-4P, 1954.

56. Rueden CT, Schindelin J, Hiner MC, DeZonia BE, Walter AE, Arena ET and Eliceir KW: ImageJ2: ImageJ for the next generation of scientific image data. BMC Bioinformatics 18: 529, 2017.

57. R Core Team (2021). R: A language and environment for statistical computing. R Foundation for Statistical Computing, Vienna, Austria. URL http://www.R-project.org/.

58. Kuo SH, Erickson-Davis C, Gillman A, Faust PL, Vonsattel JP and Louis ED: Increased number of heterotopic Purkinje cells in essential tremor. J Neurol Neurosurg Psychiatry 82: 1038-1040, 2010.

59. Symanski C, Shill HA, Dugger B, Hentz JG, Adler CH, Jacobson SA, Driver-Dunckley E and Beach TG: Essential tremor is not associated with cerebellar Purkinje cell loss. Mov Disord 29: 496-500, 2014.

60. Lance $J$ and McLeod J (eds): The cerebellum and its disorders. Chapter 8. In: A Physiological Approach to Clinical Neurology. 3rd edition. Butterworth-Heinemann, Oxford, pp191-218, 1981.

61. Rilling JK: The Evolution of the Cerebellum in Anthropoid Primates. Chapter 10. In: Evolution of Nervous Systems. Kaas J (ed). Volume 4. 2nd edition. Academic Press, Oxford, pp149-156, 2007.

This work is licensed under a Creative Commons Attribution-NonCommercial-NoDerivatives 4.0 International (CC BY-NC-ND 4.0) License. 